\title{
WAVE INTERACTION WITH DECK OF JETTY ON A SLOPE
}

\author{
Yanqiu Meng ${ }^{1}$ and Guoping $\mathrm{Chen}^{2}$, Shichang Yan $^{3}$
}

\begin{abstract}
Experimental investigations were carried out on wave-induced uplift loads on deck of shore-connecting high pile jetty on a slope in regular waves. A study on effect of gap (between deck end and shore line) on wave impact was also performed. It is found that the maximum uplift loads generally lag behind the maximum impact pressure and are associated with the pressure uniformly distributed along deck. Analysis of the measured data confirms that the distribution length for the uniform pressure is equivalent to wave contact length $x$. When $x$ is larger than the width of $\operatorname{deck} B$, it is taken as $B$. The non-dimensional uplift load increases with the increased relative deck clearance $\Delta h / \eta$. The increasing tendency continues up to $\Delta h / \eta=0.2$ and at that location the wave uplift load reaches a peak. After that, the load decreases until at certain deck level the above trend of load start to repeat once more. Generally, two peaks of wave uplift load occur in the range of deck clearance tested. The magnitude of the second wave load peak is larger than the first one. The non-dimensional wave force is observed to increase when the ratio of the wave length to the deck width increase up to a certain ratio. Beyond that ratio the force is less sensitive to the variation of the deck width. It is also found that the force reduces with increase in gap width. This decreasing trend of force is favorable for the design. From the investigation with wide range of input wave and structure parameters, simple predictive equation for wave uplift load was proposed for regular waves.
\end{abstract}

Keywords: regular wave; uplift forces; high-pile jetty; slope

\section{INTRODUCTION}

In rough seas, deck slamming may occur with large wave impact forces for jetties. Great wave impact loads may affect the function of jetties and threat the safety of jetties. Recently damages of deck of ocean structure like jetties, bridges and offshore platforms exposed to wave action have shown wave-in-deck uplift loads are very critical in design superstructures. Therefore how to reduce the wave induced uplift loads on deck is a great challenge for coastal engineers. Selection of a very high deck clearance to escape the wave action maybe useful on reducing the wave uplift loads on deck. However the higher the deck clearance, the more expensive the jetty construction costs. Hence, taking decisions of deck clearance is essential for safety and economics of jetty. From this point of view, a detailed knowledge of wave interaction with deck of jetty on a slope is needed for optimum design of jetty.

There are several researches reported on wave actions for flat plate and deck of jetty. In some investigations, based on momentum and energy considerations, the forces were typically modeled as the rate of change of momentum of water as wave hitting the element (Wang, 1970; El Ghamry, 1971; Tanimoto and Takahashi, 1979; Broughton and Horn, 1987). A situation of particular relevance that has been examined by some researchers is that of wave slamming on cylinders. The wave slamming force evaluated at the moment of contact is generally expressed in terms of the slamming coefficient $C_{s}$. Experimental measurements have yielded the slamming coefficient range. Suchithra and Koola(1995) investigated the wave impact on horizontal slabs and found the slamming coefficient vary between 2.5 and 10.2. The structural dynamics and air entrainment is responsible for the wide range of slamming coefficients indicated above. The effect of wave impact on deck is more related to the slamming forces on a ship hull, so knowledge from studies on hull slamming is a likely approach to further research targeted for the coastal engineer. Kaplan and Silbert(1976),Kaplan(1979,1992),Kaplan et al(1995) extended the theory of ship bottom slamming to the case of flat decks and horizontal beams on offshore platforms, and expressed the vertical loads as the combination of momentum and drag components. Goda(1967) investigated the impulsive uplift load on deck of exposed trestle bridge in deep water. Guo da et al (1980) present a method for estimating uplift force on deck with different configurations. Isaacson and Bhat(1994), Isaacson et al.(1994) studied the vertical force due to regular non-breaking waves acting on a horizontal plate. Bea et al. (2001) took account of dynamic response of structural elements in analyzing wave induced loads. Based on the dynamic characteristics of the jetty model, Cuomo $(2005,2007)$ applied wavelet tools filtering out corruptions from the dynamic response of the model setup and distinguishing the impulsive and quasi-static wave loads. Cuomo (2009)

\footnotetext{
${ }^{1}$ Key laboratory of coastal disaster and defendce ministry of education, Hohai University, No.1 Xikang Road, Nanjing, Jiangsu,210098, China

${ }^{2}$ College of Coastal, Harbor and Offshore Engineering, Hohai University, No.1 Xikang Road, Nanjing, Jiangsu, 210098, China

${ }^{3}$ College of Coastal, Harbor and Offshore Engineering, Hohai University, No.1 Xikang Road, Nanjing, Jiangsu, 210098, China
} 
presented insights on the dynamics of wave-loading of coastal bridges and discussed the effect of openings in deck through large-scale experiment.

The available literatures on wave interactions with deck are mainly focused on studies with exposed jetty and limited quantitative attempt has been made on guidance for design of deck of shoreconnecting jetty on a slope. Variability in the previous methods led to some confusion in the application of such predictions to design situations. Therefore, a practical prediction for wave uplift loads on deck of jetty on a slope was required for the safe design of jetty and similar ocean structure.

\section{EXPERIMENTAL SETUP AND PROCEDURE}

The wave tests were conducted in the $80 \mathrm{~m}$ long, $1.0 \mathrm{~m}$ wide, $1.2 \mathrm{~m}$ deep wave flume of Key Laboratory of Coastal Disaster and Defendce Ministry of Education, at Hohai University in Nanjing, China. Regular waves were generated by a wave maker at one end of the flume. Mild slope were laid at two ends to mitigate wave reflection on boundaries. The model test section (scale 1:36 to typical prototype structure) comprised a typical jetty head constructed from down-standing cross-beams (cross: $20.75 * 2 * 5 \mathrm{~cm}^{3}$, transverse: $\left.102 * 4 * 8 \mathrm{~cm}^{3}\right)$ and a solid deck $(49.5 \mathrm{~cm}$ wide, $1.5 \mathrm{~cm}$ thick). Three force transducers and twenty pressure gauges were fitted in the deck, which recorded load measurements at a sampling frequency of $125 \mathrm{H}_{\mathrm{z}}$. Water depth at the jetty model was $d=0.5 \mathrm{~m}$. The test covered a range of wave conditions (incident wave height $H=0.1-0.2 \mathrm{~m}$; incident wave period $T=1.0-2.5 \mathrm{~s}$ ). Six different ratios of clearance to the significant incident wave height $\Delta h / H$ were tested: $\Delta h / H=0,0.1,0.2,0.3,0.4$, 0.6 , achieved by raising the deck. The experimental setup and a sketch of the tested configuration are shown in Fig. 1 and Fig. 2.

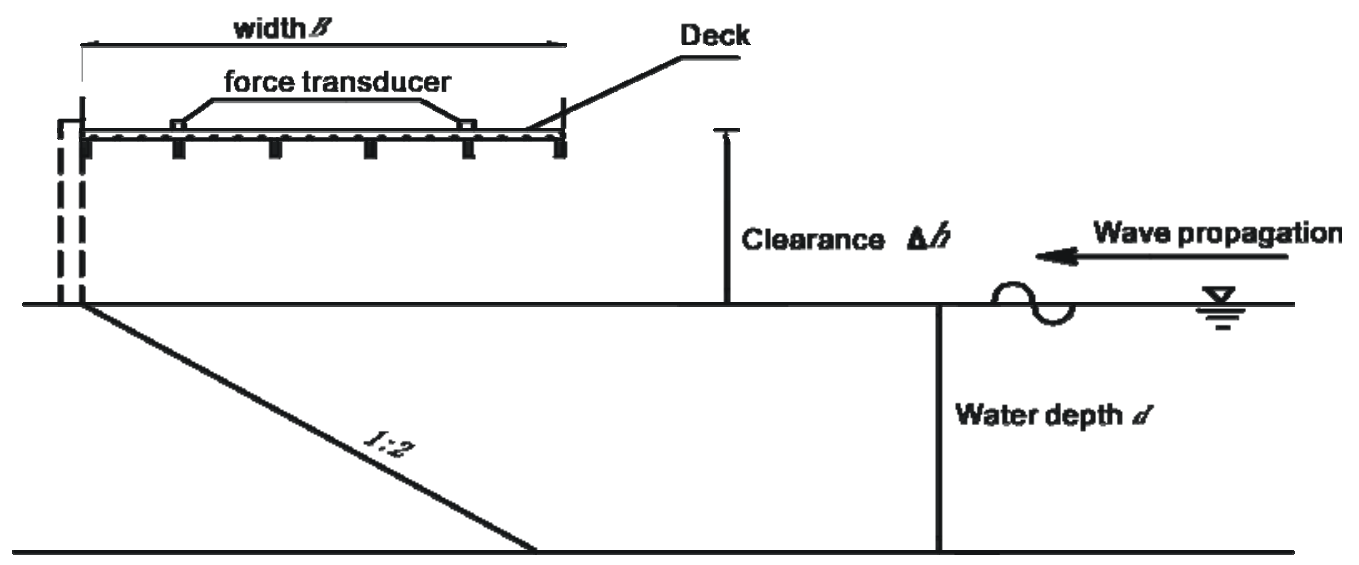

Figure1. Sketch of experimental setup from side view.

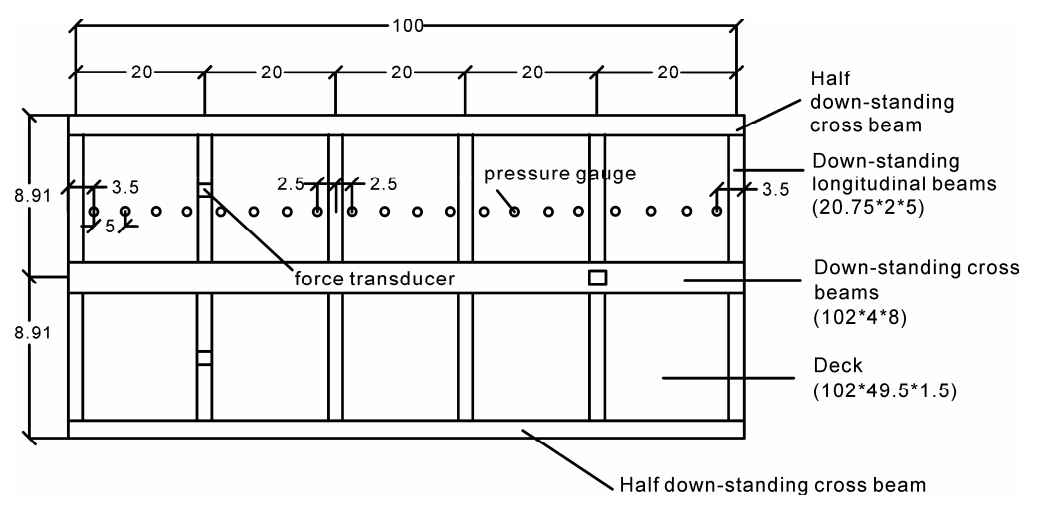

Figure 2. Underside of model deck. (unit:cm) 


\section{RESULTS AND DISCUSSIONS}

\section{Distribution Length Associated with Uplift Force on Deck}

From a practical point of view for designers, the required quantities are not only the magnitude of force, but also the corresponding spatial distribution of pressure. The spatial pressures distribution associated with uplift forces have been categorized based on a combination of direct observation and measurement. Examples of spatial distribution of pressure along deck classified as sharp-spike like type and uniform type from tests are presented in Fig.3. It is found that the maximum uplift loads generally lag behind the maximum impact pressure and are associated with the pressure uniformly distributed along deck. The top one exhibits sharp-spike-like distribution, which comprises a church roof form within localized area and a rapid decrease to small magnitude in other area on deck. Peak values occurred as the wave hitting on the deck. The total force in the top panel is not large as expected due to the small area weakening the effect of peak pressure. The bottom panel refers to uniform distribution with a comparative small pressure but across large area, which is associated with the maximum uplift load. For the purposes of the present investigation, the uniform distribution is informative for designers. Although uplift loads have been widely investigated, few studies have been done on the corresponding pressure distribution length. The estimation of the distribution length changes between different authors and methods. For example Goda uses $L / 4$, and that Guoda uses $L / 9 \sim L / 6$. It is common that for simplicity, the distribution length formula above were both assumed to be proportional to the wave length with a constant ratio. The values related to identical wave length would remain constant even for different clearances, which is clearly inconsistent with the phenomenon recognized in experiment.

It is worth noting that the distribution length observed from tests increased with increasing wave length, but decreased with increasing clearance. Application of the above formula to describe the distribution length would give rise to a relatively larger error in estimating forces especially for deck at large clearance. So in this paper, new equation was developed to provide designers with reasonable prediction model. It is seemed that the most informative variable is $x$, the contact length of wave at deck level, identified in Eq.1.

$$
\begin{gathered}
x=\frac{L}{\pi} \arccos \left(\frac{\left.-1+\sqrt{1+\frac{8 \pi H}{L} f\left(\frac{d}{L}\right)\left[\frac{\pi H}{L} f\left(\frac{d}{L}\right)+\frac{2 \Delta h}{H}\right]}\right)}{1.5 * \frac{4 \pi H}{L} f\left(\frac{d}{L}\right)}\right) \\
f\left(\frac{d}{L}\right)=\frac{\operatorname{ch} \frac{2 \pi d}{L}\left(\operatorname{ch} \frac{4 \pi d}{L}+2\right)}{4\left(\operatorname{sh} \frac{2 \pi d}{L}\right)^{3}}
\end{gathered}
$$

When the deck clearance is small, the Eq.3 can be used.

$$
x=\frac{L}{\pi} \arccos \left(\frac{\Delta h}{1.5 * \eta}\right)
$$

Where $x=$ the contact-length of wave at deck level (associated with $\eta, L), L=$ incident wave length, $\Delta \mathrm{h}=$ clearance (i.e. vertical distance between an element and s.w.1.). For a given $H, L$, the value of $\eta$ is then taken as the maximum crest elevation for a wave propagating in water of constant depth $d$, see Eq. 4.

$$
\eta=\frac{H}{2}+\frac{\pi H^{2}}{2 L}\left[\frac{\operatorname{ch} \frac{2 \pi d}{L}\left(\operatorname{ch} \frac{4 \pi d}{L}+2\right)}{4\left(\operatorname{sh} \frac{2 \pi d}{L}\right)^{3}}\right]
$$

Variable $x$ is more strongly linked to the loading process as it takes into account the dependence of wave length and clearance. Analysis of the experimental data confirmed that the distribution length is almost equivalent to $x$. When $x$ is larger than the width of deck $B, B$ is then used as the distribution length. It should be noted that for deck with beams the effect of wave reflection from beams was recognized in calculating $x$ by introducing the coefficient 1.5, see Eq.1 and Eq.3. 


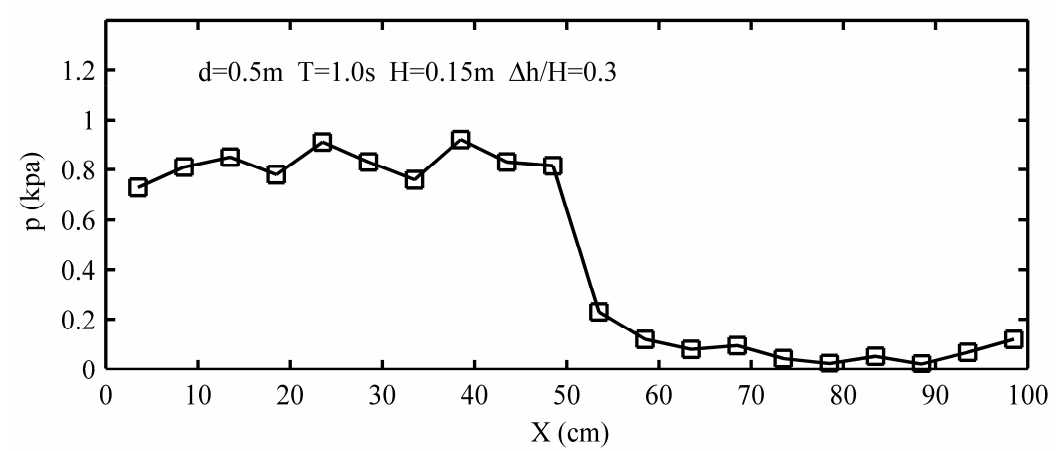

Figure 3a. Simultaneous horizontal pressure distribution at the instant of greatest uplift force on the deck (The corresponding contact length $x=0.43 \mathrm{~m}$ ).

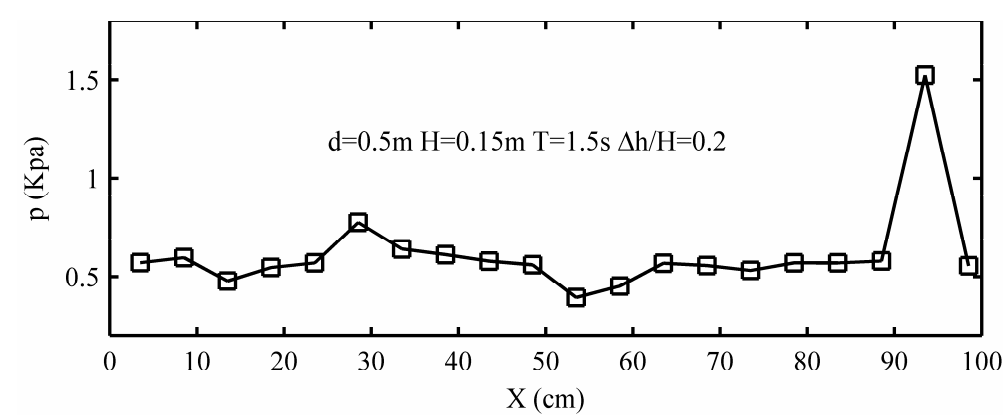

Figure 3b. Simultaneous horizontal pressure distribution at the instant of greatest impact pressure on the deck (The corresponding contact length $x=0.95 \mathrm{~m}$ ).

\section{Wave-in-deck Uplift Loads on deck of shore-connecting high pile jetty on a slope}

\section{Parametric analysis of the effect of geometric and hydrodynamic variables}

In order to analyze the observed force signals created by the random waves in tests, it is necessary to relate the uplift force to properties of the wave events and structure configurations. On the basis of a dimensional analysis, the uplift force $F$ on the deck is influenced by variables as $H, L, T, d, \Delta h, \eta, B$. Variable $B$ denote the width of deck in wave propagation direction. Analysis of data measured confirmed that the dominant variables were $H, L, \eta, \Delta h, B$. Forces tested in this project implied noticeable trends between the maximum uplift loads and the composite variable $L / B, \Delta h / \eta$.

\section{Effect of clearance}

Dimensionless uplift load on deck $p=P /(\rho g H x)$ vs. the relative clearance $\Delta h / \eta$ is plotted in Fig.4. Where $P$ denotes the maximum value of the wave-in-deck uplift force per unit length of deck, and the direction of that length is perpendicular to the wave propagation direction.

Clear trend of the dimensionless uplift load with the relative clearance can be seen in Fig.4. The increasing tendency continues up to $\Delta h / \eta=0.2$ and at that location the wave uplift load reaches a peak. After that, the load decreases until at certain deck level the above trend of load start to repeat once more. Generally, two peaks of wave uplift load occur in the range of deck clearance tested. The magnitude of the second wave load peak is larger than the first one. As the deck rises to a certain level where the wave is below the clearance, the wave crest can not touch the deck and the force becomes zero. It should be noted that the forces experienced by the deck with beams show different behavior which is influenced by the deck configuration. For deck with beams, the clearances relevant to the peak force and the zero force tend to be large and the force decrease slowly with increasing clearance. Owing to the wave reflecting from the downward beams interact with the incoming waves and result in an increase of the wave height. 


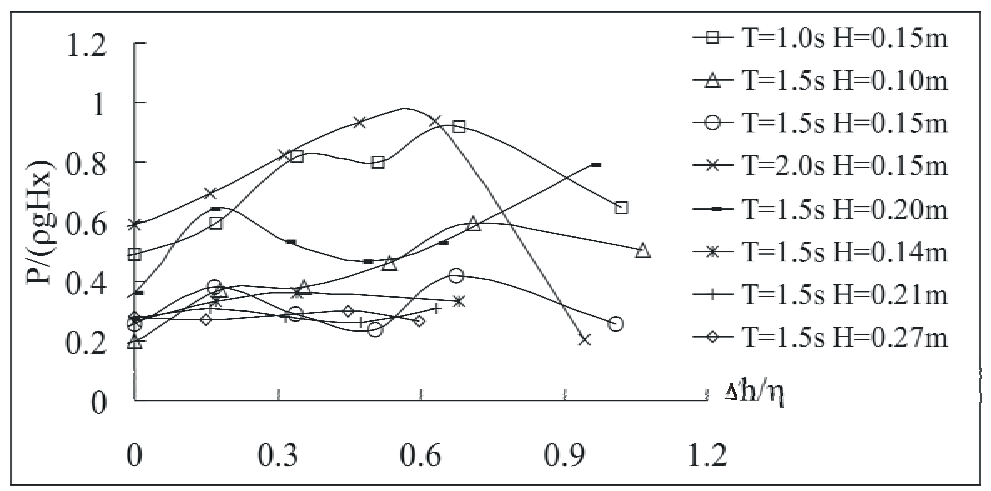

Figure 4. Dimensionless maximum uplift force versus the relative clearance.

\section{Effect of deck width}

Uplift forces on deck are presented in Fig.5 and Fig.6 for loads $F$ and dimensionless loads $p$ respectively, plotted against the composite variable $L / B$. It is seemed that forces are sensitive to the deck width in wave attack direction. The response of forces with $L / B$ is clear from the plot. From Fig.5,

the forces tend to increase as the deck width increases at first, then the increase slow down and the force remain constant after the deck width increase to a certain value, in some cases the force showed slightly decrease. The trends of forces can be explained as follows: For short deck the width of which is smaller than the width of contact region between wave and deck (that is the contact length mentioned above), the whole deck is exposed to the wave attack and the longer the deck, the larger the total forces. The forces keep constant when the deck width is almost equal to the contact length. For deck becomes further longer, the force decreases with the increasing deck length, which is due to the deck is subjected to the action of both the crest and the trough and the combined effect result in weakening the total force. Assuming the deck width is larger than one times wave length, the total forces increase in respect that the deck experience more than one wave. Therefore, taking in account of wave length as the pressure distribution length makes the force always increase with $L / B$ increasing even for the deck longer than wave contact length but shorter than one wave length. This disagrees with the above trend observed in tests. From this point of view, it is once more showed that the assumption of the pressure distribution length related to wave length is not reasonable.

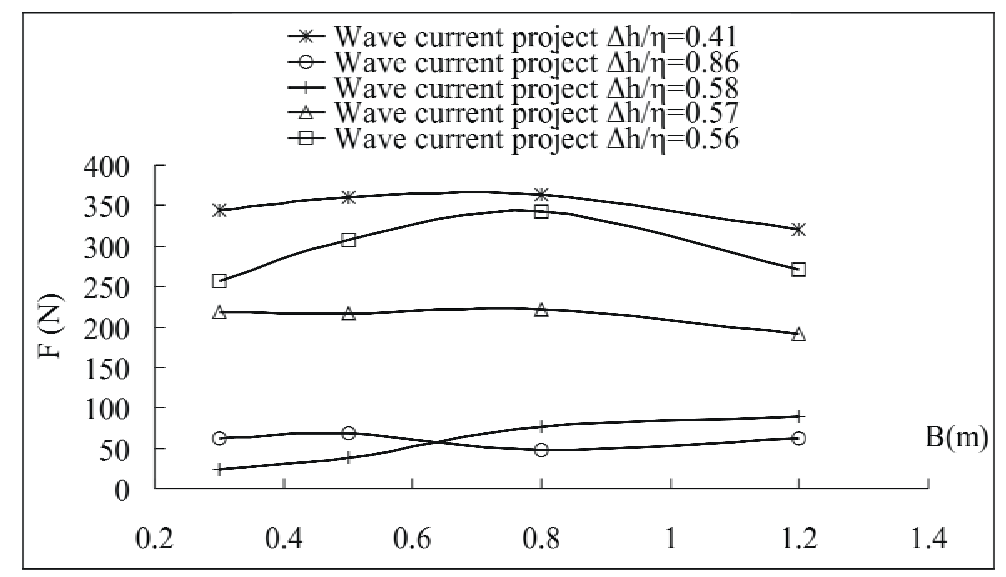

Figure 5. Maximum uplift load $F$ versus the width of deck $B$.

A clear dependence of dimensionless uplift forces on $L / B$ is illustrated in Fig.6. The trends of dimensionless force with the composite variable $L / B$ show that the force tends to decrease as the deck width increases (namely the ratio of $L / B$ decreases), then the decrease slows down when the deck width exceeds or is beneath a certain value. It attribute to the following mechanics: First; for deck with width much shorter than the contact length of wave, the action of wave concentrates on the contact region, the pressure distribution on deck are almost constant, thus slightly decreasing or increasing of the deck width has little influence on the total force. Second; with the deck width increasing in the limit of no more than the contact length, the slightly non-homogeneous of wave action on deck is responsible to 
the dimensionless total forces decrease. Third; after the deck width is in excess of the contact length, the total forces increased little, the pressure distribution length equals to the contact length and remains unchanged, therefore the dimensionless forces appears almost constant.

\section{Prediction model of uplift loads}

Based on the analysis in the above section, the dominant variables for the loading process were found to be the incident wave height $H$, the incident wave length $L$, the maximum crest elevation $\eta$, and the clearance of the element above the s.w.l. $\Delta h$, the deck width $B$. New prediction method were developed using the following dimensionless variables: $p, \Delta h / \eta, L / B$. Trends of dimensionless forces $p$ with $\Delta h / \eta$ and $L / B$ are generally recognizable among data from tests run. Eq. (5) and Eq.(6)has therefore been proposed to predict the maximum uplift load $P$ :

$$
\begin{gathered}
P /(\rho g x H)=K_{B} *\left(1-\frac{\Delta h}{1.5 * \eta}\right)^{0.3} * e^{\left(-1.5^{*}\left(\frac{\Delta h}{1.5^{*} \eta}-0.5\right)^{2}\right)} \\
K_{B}=(1.8+1.5 * \tanh (0.2 *(L / B-5.5)))
\end{gathered}
$$

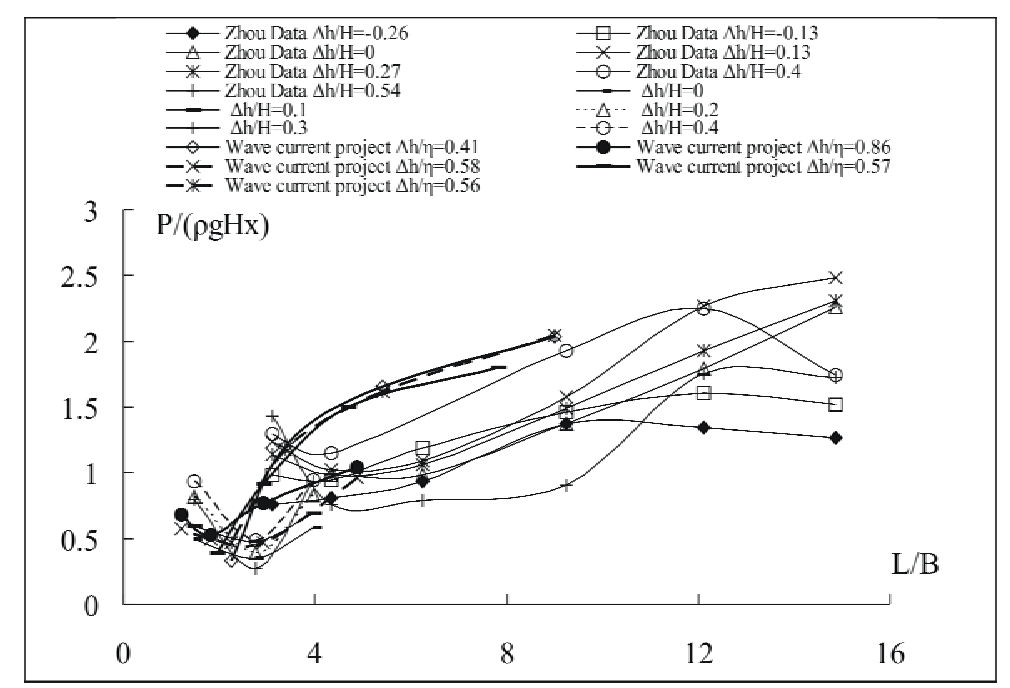

Figure 6. Dimensionless maximum uplift load $P /(\rho g H x)$ versus $L / B$.

\section{Comparison of uplift force with new prediction method}

Predictions of wave-in-deck uplift loads by Eq. 5 and Eq. 6 are compared with the measured data in Fig.7. The comparison shows that the new prediction method gives a good result on uplift forces.

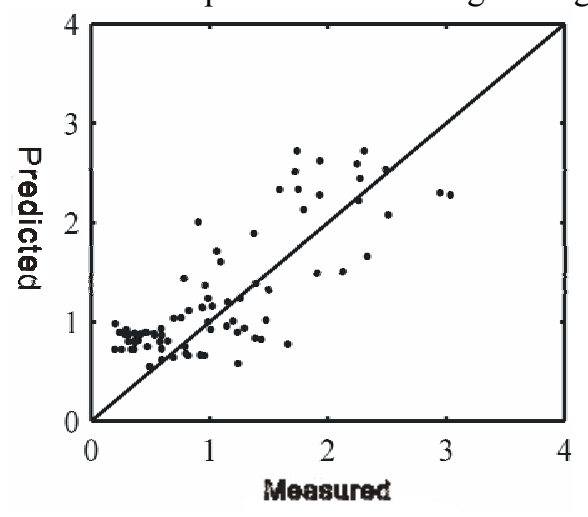

Figure 7. Comparison of the measured dimensionless uplift forces with the proposed new prediction method

The influence of setting gap and hole in deck on wave uplift forces 


\begin{tabular}{|c|c|c|c|c|c|c|}
\hline \multicolumn{6}{|c|}{ Table.1 Comparison of uplift force on deck closed, deck with gap, deck with hole } \\
\hline $\mathrm{Fi} / \mathrm{F}_{1}$ & $\mathrm{i}=1$ & $\mathrm{i}=21$ & $\mathrm{i}=22$ & $\mathrm{i}=23$ & $\mathrm{i}=31$ & $\mathrm{i}=32$ \\
\hline $\mathrm{H}=0.10 \mathrm{~m}$ & 1 & 1.250 & 0.912 & 1.004 & 0.840 & 0.699 \\
\hline $\mathrm{H}=0.15 \mathrm{~m}$ & 1 & 1.274 & 1.158 & 1.029 & 0.933 & 0.703 \\
\hline $\mathrm{H}=0.20 \mathrm{~m}$ & 1 & 0.824 & 0.923 & 0.976 & 0.813 & 0.799 \\
\hline
\end{tabular}

Where: $i=1$ shore-conecting; $i=21$, gap width $=2 \mathrm{~cm} ; i=22$, gap width $=3 \mathrm{~cm} ; i=23$, gap width $=4 \mathrm{~cm}$; $\mathrm{i}=31$, hole number $=3 ; \mathrm{i}=32$, hole number $=5$.

In order to investigate the effect of two measures, which are laying gap between deck and shore and setting holes in deck, on reducing wave impact on superstructure of shore-connecting high-pile jetty on a slope, regular wave tests were conducted in wave flume. The influences of setting gap and opening hole on magnitude of uplift load have been studied based on analysis of data collected in tests. Results obtained from tests show that generally the uplift force reduces with increase in gap width. Moreover, the uplift force decreases due to opening holes in deck and the more the number of holes increases, the more the load decreases.

\section{CONCLUSIONS}

This paper builds upon investigation on wave-in-deck uplift force. The force was examined by a series of model tests.

The spatial distribution of the wave pressure has been established. Two different types were illustrated. Based on the experimental data, it has been verified in this study that the maximum measured uplift load was correlated with uniform type distribution of pressure along deck.

In addition, evidence of relationships between non-dimensional parameters based upon deck width and deck clearance and measured uplift forces were presented. The force was shown to strongly depend on deck clearance. The increasing tendency continues up to $\Delta \mathrm{h} / \eta=0.2$ and at that location the wave uplift load reaches a peak. After that, the load decreases until at certain deck level the above trend of load start to repeat once more. Generally, two peaks of wave uplift load occur in the range of deck clearance tested. The magnitude of the second wave load peak is larger than the first one. The non-dimensional wave force is observed to increase when the ratio of the wave length to the deck width increase up to a certain ratio. Beyond that ratio the force is less sensitive to the variation of the deck width. It is also found that the force reduces with increase in gap width. This decreasing trend of force is favorable for the design. From the investigation with wide range of input wave and structure parameters, simple predictive equation for wave uplift load was proposed for regular waves.

\section{REFERENCES}

Bea, R.G., Iversen, R., Xu, T., 2001.Wave-in-deck forces on offshore platforms. J. Offshore Mech. Arct. Eng. 123: 10 21.

Broughton, P., Horn, E., 1987. Ekofisk Platform 2/4C: re-analysis due to subsidence. Proc. Inst. Civ. Eng. 1 (82), 949-979 (Oct.).

Cuomo, G., Tirindelli,M. and Allsop, N.W.H., 2007. Wave-in-deck loads on exposed jetties. Coastal Engineering,54(9):657-679.

Cuomo, G., Shimosako, K. and Takahashi, S., 2009. Wave-in-deck loads on coastal bridges and the role of air. Coastal Engineering,56(8):793-809.

El-Ghamry, O.A., 1965. Wave forces on a dock. Technical Report HEL-9-1, Hydraulic Engineering Laboratory, Institute of Engineering Research.University of California.

Goda, Y. , 1967. Wave forces on structures , Summer Seminar on Hydraulics, JSCE , B34. (in Japanese)

Guo D. and Cai B.H., 1980. Calculation of uplift forces of waves on plates for hollow trussed structures , Journal of East China Water Resources University, (1) : $14 \sim 33$. (in Chinese)

Isaacson, M., Bhat, S., 1994. Wave forces on a horizontal plate. International Symposium: Waves Physical and Numerical Modelling. University of British Columbia, Vancouver, 1184-1193.

Isaacson, M., Allyn, N., Ackermann, C., 1994. Design wave loads for a jetty at Plymouth, Montserrat. International Symposium: Waves - Physical and Numerical Modelling. University of British Columbia, Vancouver, 1153-1162.

Kaplan, P., Murray, J.J., Yu, W.C., 1995. Theoretical Analysis of Wave Impact Forces on Platform Deck Structures. Offshore Technology OMAE, vol. I A.ASME, 189-198. 
Kaplan, P., 1992.Wave impact forces on offshore structures: re-examination and new interpretations. Paper OTC 6814, 24th Offshore Technology Conference, Houston, 79-98.

Kaplan, P., 1979. Impact forces on horizontal members of an offshore test structure. Proc. of Civ. Eng. in the Oceans IV, San Francisco, CA, USA.ASCE, New York, 716-731.

Kaplan, P., Silbert, M.N., 1976. Impact forces on platform horizontal members in the splash zone. TX OTC, Huston, Proc. of the Offshore Technology Conference, 749-758.

Suchithra, N., Koola, P.M., 1995. A study of wave impact on horizontal slabs. Ocean Eng. 22 (7):687697.

Tanimoto, K., Takahashi, S. and Izumida, Y., 1979. Wave Forces on a Horizontal Platform. Proc. of the 5th Intern Ocean Dev. Conf., Tokyo, D1-29 to D1-38.

Oumeraci, H., 1994. Review and analysis of vertical breakwater failures - lessons learned. Coastal Engineering 22, 3-29.

Oumeraci, H., Kortenhaus, A., Allsop, N.W.H., De Groot, M.B., Crouch, R.S.,Vrijling, J.K., Voortman, H.G., 2001. Probabilistic Design Tools for Vertical Breakwaters. Balkema, Rotterdam. ISBN: 90 $5802488,392 \mathrm{pp}$.

Ren B., Li X.L., Wang Y.X.. 2007. Experimental investigation of instantaneous properties of wave slamming on the plate. China Ocean Engineering, 21(3):533-540.

Wang, H., 1970. Water wave pressure on horizontal plate. Journal of the Hydraulic Division. ASCE, 1997-2016. No.HY10 Oct.1970.

Witte, H.H., 1988. Wave induced impact loading in deterministic and stochastic reflection. MittLeichtweiss Inst. Wasserbau, vol. 102. Tech. Univ.Braunschweig, Braunschweig, Germany.

Zhou Y.R., Chen G.P., Huang H.L., et al. 2004.Experimental study on uplift forces of waves on a horizontal plate an open-wharf. Journal of the Ocean Engineering, 22(4):43-50. (in Chinese)

Zhou Y.R, Chen G.P., Huang H.L., et al. 2003. Uplift pressure of waves on a horizontal plate. China Ocean Engineering, 17(3):355-368. 